\title{
Pricing Determinants of selected Fixed Price IPOs issued in India
}

\author{
*Harmohan Singh Dhall ${ }^{1}$, Dr. Sukhdev Singh ${ }^{2}$ \\ ${ }^{1}$ Research Scholar, Punjab Technical University, Kapurthala \& Asstt. Professor,Department of Business \\ Administration, Guru Nanak Dev Engineering College, Ludhiana, India \\ ${ }^{2}$ Professor \& Head, Department of Business Administration, Guru Nanak Dev Engineering College, Ludhiana, \\ India
}

\begin{abstract}
This paper is an attempt to examine the valuation factors affecting the pricing of Initial Public Offerings (IPOs) issued in India through fixed price mechanism and listed on BSE between 2010-2016. A total of 46 fixed Price IPOs were investigated for the impact of age of the company, revenue, net profits, net asset value per equity share, issue size, return on net worth, earnings per share, industry profits to earnings ratio and promoter's shareholdings. The paper reveals that net asset value per share and net profits are positively correlated with both the offer price and listing price while issue size is negatively correlated with the offer price. Further the regression result also computed a significant impact of net asset value per share and net profits on the two pricing points.
\end{abstract}

Keywords: valuation factors, fixed price IPOs.

\section{Introduction}

An Initial Public Offer (IPO) is a process in which a company goes public by offering its equity shares or convertible securities to the public in the primary market. At a certain point in the development of a firm, it decides to raise the funds through an IPO and shifts the ownership from closely held private firm to widely held public firm. IPOs in India are governed by the SEBI (Security Exchange Board of India) and the company which issues the IPO needs the permission from SEBI for doing so. Under the control of SEBI, issuers can freely price their offerings subject to obligation for the firms to make a sufficient disclosure in the offer documents.It is frequently presumed that the market prices are not reflecting all necessary information as inferred from the partial aggregation of the financial markets, particularly that which is unavailable publicly. Managers can choose the indirect signals, for instance dividend policy given by Bhattacharya $(1979)^{[1]}$ and financial leverage as concluded by Ross $(1977)^{[2]}$, or direct signals, via complete revelation about the company as determined by Hughes $(1986)^{[3]}$, with the help of distributing unambiguous indications concerning the future performance of the firm to the public.

Cassia $(2004)^{[4]}$ examined that the IPO's floated through fixed price mechanism were highly underpriced than those issued with the book building mechanism. Pastor and Veronesi $(2005)^{[5]}$ evaluated that the over valuation of the IPOs led to an elevation in the IPO size. Adams et al (2008) ${ }^{[6]}$ explored that the IPOs with larger size are more underpriced as compared to those with smaller issue size. Further the investors behaved irrationally as the initials returns were less during the normal times as compared with the bull markets. Samdani and Gupta (2010) ${ }^{[7]}$ witnessed more of a representative behavior shown by the investors on fixed price IPOs. Also, there was an optimistic reaction from the investors for the issues with large offerings and hot issues.

The major challenge being confronted by the IPO firms during their process of going public is the criteria to price their offers. Yet it is much more perplexing for the investors as well as the practitioners comprising academic scholars. It was founded through empirical studies that IPOs valuation takes place through the following methods - directly by taking fundamental accounting statistics, or indirectly by the comparison of the IPO firm with related listed company/companies from equivalent industry. Though the most accepted method of valuation is multiple approaches, in spite of that experts found referring financial figures and other signaling, whilst endorsing the investment in an IPO. Regardless of plenty of study on valuation, still IPO pricing is unsolved.

Fixed pricing is the method in which companies are free to price their securities while in book building method the demand and price of the securities is determined through the bidding method. A fixed priced public issue should be kept open for 3-10 working days, whilst, for book building it is 3-7 workings days which can be extended by 3 day if a need for price band revision arises. Moreover, unlike book building method, in fixed price the allocation of shares needs to be in proportion to the quantity bid. Under the fixed price mechanism, issuing company determines the price of the equity shares that are to be made public. Further, price at which these securities would be allotted is known to the investors in advance. Only after the closure of the issue, the response of the securities could be computed. According to the SEBI guidelines the basis for the issue price, 
both qualitative and quantitative, must be disclosed in the offer document so as to justify the issuing price. The basis for issue price must contain the following parameters, i.e. Earnings per Share (EPS), Price to Earnings Ratio in relation to issue price, Return on Net worth (RONW) and Net Asset Value (NAV).

\section{Review Of Literature}

Krinsky and Rotenberg $(1989)^{[8]}$ examined relationships between the market value of equity share offerings with prospective signaling procedures such as the proprietorship holding by the entrepreneur, the quality of the underwriter chosen, issue profits deployed in exploration and development activities, sales revenue and profits from the previous year, total value of assets preceding to the initial offerings. The study found a significant relationship of all the signals with the value of IPO except the historical revenue, profit margins and the ownership retention It also supported the role of information providers in the valuation as they act as mediators in the public and the entrepreneur.

Benveniste and Busaba (1997) ${ }^{[9]}$ studied the two most widely used methods of IPOs, fixed price offer and book building. Their analysis showed that optimization of both the methods depends on the features of the issuer, and proposed that the incompetency in the new equity markets may be contributed to the regulations which restrain the underwriters to one or the other. Book building produce elevated expected returns thus allowing the issuer to sell the securities at full value but in it the exposure to risk is higher, whereas, fixed priced offerings places issuer in guaranteed certain profits even though at lower prices.

Barker (1999) ${ }^{[10]}$, Bradshaw (2002) ${ }^{[11]}$, observed that the P/E standard was used extensively for evaluating an IPO. On examination of 103 specialist information (in USA), Bradshaw found that the experts made use of P/E method and anticipated its evaluation to be an important value motivator for equity. Aggarwal $(2003)^{[12]}$ reported that, whilst trading volume in the initial two days was $74 \%$, and only $7 \%$ of the total offered shares offered in the IPO are flipped.

Yeh et al (2008) ${ }^{[13]}$ inspected the impact which was made on the evaluation of IPO firms of Taiwan by the pattern of ownership. Fixed price IPOs were used to assess the impact. A negative correlation was found in the study between the cash structure and the voting structure of shareholders. Pukthuanthong-Le \& Varaiya $(2007)^{[14]}$ concluded that IPOs that were overly valued showed higher block sales as compared to the lower valued IPOs. They also found that block selling could also foretell the performance of long term IPOs. Conclusion was made from the results that at the offering dates, the higher block sale IPOs were overly valued $\&$ that the lower block sales IPOs were mostly undervalued. It was also observed that between the lockup expiration \& before 3 years of the start of offerings, the difference was reversed. Lin and Hsu (2008) ${ }^{[15]}$ in their study of 'Determinants of the initial IPO performance: evidence from Hong Kong and Taiwan' came to the conclusion that initially IPO firms outperform their markets both in Hong Kong \& Taiwan by $6.09 \%$ \& $2.57 \%$ respectively. Moreover SMEs in both of these markets were not at disadvantage as compared to other large counterparts. Their findings supported Rock's (1986) adverse selection theory which argued that underpricing of the IPO shares are done so as to minimise the winners' curse for uninformed investors.

Smart \& Zutter $(2008)^{[16]}$ focussed on the differences in underpricing between the single \& the dual class IPOs so as to find out the variation which was made by the alternative methods. It was found that generally, the various alternative approaches of estimation gave a hint of lower underpricing. It was concluded that there were 2 methods available for the researchers to find out the estimates when due to the price stabilisation, the observed returns did not reflect true underlying distribution of the initial returns. In the first method, it was assumed that for some of the deals, the true return was not reflected by the observable returns. In the second method we can ascertain the underpricing over a longer period of time. The results obtain by both these 2 cases were similar.

Aggarwal et al (2009) ${ }^{[17]}$ observed that mostly IPOs with positive earnings are considered for evaluation and analysis which leads to limited findings. They reveal that IPOs with large negative earnings have been showing higher correlation with higher valuations in the study period in the selected industry category. Gupta and Samdani $(2010)^{[7]}$ recognized that the representative behavior was shown by the investors on the IPOs issued with fixed price mechanism. An optimistic reaction of the investors was seen on the issue offerings made in large scale and for the hot issue IPOs. Lowry et al $(2010)^{[18]}$ exhibited that the initial offerings market was underpriced, which proposed that the volume of IPOs issued was in a proportionate relationship with the sentiments of the investors and capital requirement of the firms.

Alvarez (2015) ${ }^{[19]}$ analyzed the effect of IPO initial return volatility on the valuation of firms that had gone public. The process of marketing new issues to investors was not able to resolve the uncertainty of the aggregate demand for the stocks of IPOs. The firms are aware of the real demand for shares but they don't include it in the final IPO pricing. When there is more information being made public, there is lower degree of uncertainty and thus lower underpricing. The results for the variance portion of the MLE were analyzed \& conclusions were made that there is a strong relation between the offer characteristics that predicted average underpricing and the volatility of underpricing. Both the hot IPO market hypothesis \& asymmetry of 
information hypothesis were confirmed in accordance to the IPO theory. However the results failed to provide support for the signaling hypothesis for underpricing. Yong $(2015)^{[20]}$ observed that the cheaply priced IPOs are able to attract more potential buyers \& thus results in higher initial return \& price spread. Low priced IPOs are more speculated by the investors as they result in more significant profits as compared to the highly priced IPOs \& IPOs listed in the main market. Mani Jindal $(2016)^{[21]}$ evaluated the pricing performance of initial public offerings to find out whether the IPOs are underpriced and overpriced. The results suggested that the shares of negative return IPOs are more underpriced than that of the positive return IPOs in the short and long term time frames. An inverse relationship of the IPOs return \& the benchmark return was found out using risk \& return analysis. The portfolio returns were found out to be more volatile than market returns. Overpriced behavior of the IPOs leads to their underperformance. On the listing day the overpriced IPOs were found out to be underpriced which lead to their underperformance. Thus it was concluded that the pricing performance of the IPOs was not superior to that of market \& only after optimization of the risk involved, the investors should invest in these IPOs.

\section{Objective Of The Study}

To evaluate the extent of impact of selected variables in the valuation of fixed price IPOs issued in India.

\subsection{Period of the study}

\section{Research Methodology}

The period of this study spans between year 2010 and 2016.

\subsection{Population of the study and sample selection}

The population of the study comprises of 166 IPOs issued in India in the time period of $2010-2016$ and listed at BSE. An IPO with any of the following conditions will be excluded from the data set - Nonavailability of the information; withdrawal; renaming, acquisition and merger of the issuing company; and the permanent or temporary closure of the issuing company after the issuing date, and the list reduced to 143 . From which filtration was done according to the issue size, 30 companies with highest issue size and 30 with lowest issue size were selected. And our effective sample is $27.7 \%$ of the universe. Following table describes the detailed sample selection methodology.

Table 1- Sample selection methodology

\begin{tabular}{|l|l|}
\hline Criterion & Number of firms \\
\hline Fixed price IPOs issued in 2010-2016 & 166 \\
\hline IPOs withdrawn for reason $1 *$ & 23 \\
\hline Final population & 143 \\
\hline Selected sample based on issue size & 60 \\
\hline IPOs withdrawn for reason 2** & 14 \\
\hline Final sample & 46 \\
\hline Percentage & $27.7 \%$ \\
\hline
\end{tabular}

*Reason 1: - withdrawal; renaming, acquisition and merger of the issuing company; and the permanent or temporary closure of the issuing company after the issuing date.

**Reason 2: - Non-availability of full information.

\subsection{Data source and collection}

The underlying data for the study has been collected from the secondary sources of data which includes the prospectus available at website (http://www.sebi.gov.in) of Securities Exchange Board of India's (SEBI). SEBI contains the whole list of companies issuing fixed price Initial Public Issues. Draft prospectus delivers the information about the financials of the firm, tentative issue price, background, promoters, etc. Apart from these annual reports of the companies were also referred for cross referring the information available in the prospectus.

\subsubsection{Data selection}

Dependent variables

i. Offer Price of IPO (OP)

We use Offer Price (OP) as the dependent variable for the pricing of IPOs. It is the price at which the shares are made available for the retail investors in the IPO issue, thus it is basically the price at which an IPO is first sold to the public.

ii. Listing Price of IPO (LP) 
Another dependent variable chosen for the study is the Listing Price (LP). It is generally the price at which the IPOs are listed on the stock exchanges. It may also be called as the closing day price of the IPO on the very first day of trading.

Independent Variables

iii. Age of the company (Age) :

One of the most popular characteristics of a company in term of maturity is the age for the firm. Companies with longer history come across lesser ambiguities in pricing as massive amount of information is accessible at the issue time. Age is basically expressed in years as the time period from the date of setting up of the company till the date on which the company goes public. Ritter $(1991)^{[22]}$ computed a negative relation in the age of the company and underpricing whereas Suchard and Singh $(2007)^{[23]}$ found a positive relation between the two.

iv. Industry P/E (Ind_P/E)

It is one of the most prominent factors which the investors consider while they are investing. It gives us the evaluation features of the industry as a whole.

Composite $\mathrm{P} / \mathrm{E}$ is roughly calculated as the ratio of the sum of market capitalizations of all the companies in an industry to the total of their net profits, respectively. This is performed after adjusting the preference dividend and tax on them. The organisations with negative EPS are not taken into consideration while composite P/E ratio calculation. If the data needed to find composite $\mathrm{P} / \mathrm{E}$ ratio is not obtainable, composite $\mathrm{P} / \mathrm{E}$ ratio is calculated as the mean of the industrial high and low P/E ratios. Average Peer group P/E ratio is positively related to the IPO price as evidenced by Cotter et al $(2005)^{[24]}$.

v. Issue Size (Size)

Issue size of an initial public offering is the number of equity shares issued multiplied by their face value. The issue size thus is a reflection of the demand in the market for the IPOs as well as the borrowing needs of the company which is issuing the IPOs at a yield which is acceptable by the issuer.

Thus, the issue size of a security is its value in total which is expressed in nominal rather than market value terms of the security being issued. In some instances the outstanding amount differs from the actual issue size, due to redeeming of some bonds or shares. Generally, higher is the issue size, lower will be the issue price.

vi. Revenue (Revenue)

Conventionally, it was believed that growing companies were ready to go public once they reached annual revenue of $\$ 100$ million in addition to having more than half of the profitability. This $\$ 100$ million revenue theory was primarily based on the idea that the company would be big enough to overcome competitive pressures as well as that it would earn the market required to sell stock to institutional buyers in IPO.

But this theory was unable to thrive, though many bankers still believe in it. Going public is a big step of going long but at the same time, it is not the final step in it. Future health of a business may suffer if an IPO is completed too early. At the same time if too much time is spent on waiting to do an IPO, it may result in an opportunity for a competitor.

vii. Net Profit (NP)

In various studies conducted regarding the IPO and profitability of the companies, it has been found that profitability of companies going public, the margin of net profit and operating profit was better in the year before IPO as compared to the earlier periods when the company was not made public. The factor which results in this improvement is that the companies influence the accounting data so as to show themselves more attractively to the potential investors before IPO.

viii. Return on Net Worth (RONW)

Return on Net worth (RONW) gives an idea of the returns which can be produced by investing in a company. While Return on Capital Employed (ROCE) gives a better insight to get a basic overview of a company's profitability in business operations, but RONW allows us to measure the returns which can be generated on the investment. RONW if used along with ROCE gives a general view of the competence, financial capability as well as the capacity of the company to produce returns on finances of the shareholders.

It is calculated as: RONW = Net Profit/Net Worth. The RONW and ROCE of a company should be greater than the interest rates prevalent during that time otherwise the economic efficiency of a company is not considered to be healthy. At the same time, many companies may report their RONW to be lower during any high investment phase or during an economic downturn.

ix. Post issue promoter's shareholding (PS)

Post Issue promoter's shareholding denotes the percentage of shares held by the promoters of the firms. Promoters include the actual owners of the organisation. As the firm issues new shares or IPOs, the promoter's shareholding is diluted and the amount of dilution depends on the shares issued and subscribed. The promoter's shareholding is eventually bound to decrease after the issuance and this seem to be effective on the subscription rate of the IPOs. Cotter et al (2005) ${ }^{[24]}$ witnessed an inverse association between post IPO issue promoter holding and the IPO offer price.

x. $\quad$ Net Asset Value Per Equity Share (NAVES) 
Net asset value per share gives the ratio of the net assets available to the shareholders to the amount of shares outstanding on the date of initial public offerings. It seems that NAV per share presents an essential valuation explanation of the IPO issue prices. Klein $(1996)^{[26]}$ observes a positive relationship between pre issue net asset value per equity share to the offer price.

\subsection{Statistical tools}

Various statistical tools used for the study are mean, median, standard deviation, skewness, kurtosis, correlation and Multivariate OLS regression. All the above mentioned statistical measures were performed using the SPSS software.

\subsection{Descriptive Statistics}

\section{Analysis And Interpretation}

\begin{tabular}{|l|l|l|l|l|l|l|l|}
\hline & Min. & Max. & Mean & Median & Std. Dev. & Skew. & Kurt. \\
\hline OP & 10.00 & 100.00 & 27.43 & 20.00 & 20.76 & 1.91 & 4.02 \\
\hline LP & 10.00 & 100.00 & 22.13 & 15.50 & 16.39 & 2.83 & 10.65 \\
\hline Age & 0.00 & 32.00 & 11.65 & 9.00 & 8.07 & 0.78 & -0.26 \\
\hline Ind_PE & 2.20 & 967.37 & 55.96 & 20.35 & 151.23 & 5.41 & 31.17 \\
\hline RONW & -14.55 & 47.36 & 8.82 & 4.19 & 12.25 & 1.30 & 1.88 \\
\hline NAVES & 4.00 & 1760.01 & 94.15 & 22.01 & 264.64 & 5.83 & 36.72 \\
\hline PS & 0.21 & 0.79 & 0.55 & 0.56 & 0.17 & 9054.41 & 3.37 \\
\hline Revenue & 22.14 & 50406.93 & 4838.85 & 925.52 & 143.67 & 2.14 & -0.87 \\
\hline NP & -323.11 & 696.30 & 60.24 & 15.18 & 14.05 & 9.37 \\
\hline Size & 304000.00 & 12000000.00 & 3703147.83 & 3190000 & 2972953.55 & 0.65 & -0.34 \\
\hline
\end{tabular}

TABLE 2 shows the descriptive statistics of the dependent as well as independent variables. The IPO are issued in the price range of Rupees 10 to 100 . The average OP for the study is 27.43 with median 20 showing that the sample is positively skewed. Further LP also ranges between Rs. 10 to 100 with a mean of 22.13 and median of 16.36. the standard deviation is 16.39. Since in both the dependent variables with difference in minimum and maximum value is high, this implies they are not evenly distributed. Mean Age is 11.65 and the median is 9 and also the value of skewness and kurtosis is 0.78 and 0.26 , respectively. This implies that Age is distributed normally for the selected sample. Although, the mean and median values are almost same but the kurtosis value is significant, implying that the data is more gathered at the center.

Ind_PE has a significantly high maximum value i.e. 967.37 as compared to the minimum value of 2.20. Also, the mean and median values are 55.96 and 20.35, suggesting that Ind_PE is positively skewed. Further examining the profitability ratio, RONW, the variance in the minimum and maximum values shows that the data is not normally distributed. Average NAVES is 94.15 and median is 22.01 , inferring that the data is positively skewed. The PS average value is 55\% and the median value is $56 \%$ means the variable is fairly distributed. Further the Size has got lower skewness and kurtosis value but higher variance in the minimum and maximum issue size suggesting that the variable is not normally distributed. Lastly, Revenue and NP are also skewed positively and the averages are 4838.85 and 60.24 , respectively. The standard deviation for both the variables is 925.52 and 15.18 , respectively.

\subsection{Bivariate Correlation Matrix}

Table 3- Bivariate Correlation Matrix

\begin{tabular}{|c|c|c|c|c|c|c|c|c|c|c|c|}
\hline \multicolumn{12}{|c|}{ CORRELATION } \\
\hline & & $\begin{array}{c}\text { Log } \\
\text { (OP) }\end{array}$ & $\begin{array}{l}\text { Log } \\
\text { (LP) }\end{array}$ & $\begin{array}{l}\text { Log } \\
\text { Age }\end{array}$ & $\begin{array}{c}\text { Log } \\
\text { Ind_P } \\
\text { E }\end{array}$ & $\begin{array}{c}\text { Log } \\
\text { RON } \\
\text { W }\end{array}$ & $\begin{array}{c}\text { Log } \\
\text { NAVE } \\
\text { S }\end{array}$ & PS & $\begin{array}{c}\text { Log } \\
\text { Revenu } \\
\text { e }\end{array}$ & $\begin{array}{l}\text { Log } \\
\text { NP }\end{array}$ & $\begin{array}{l}\text { Log } \\
\text { Size }\end{array}$ \\
\hline $\log (\mathrm{OP})$ & $\mathrm{R}$ & 1 & & & & & & & & & \\
\hline \multirow{2}{*}{$\log (\mathrm{LP})$} & $\mathrm{R}$ & $373 * *$ & 1 & & & & & & & & \\
\hline & Sig. & .005 & & & & & & & & & \\
\hline \multirow[t]{2}{*}{ Log(Age) } & $\mathrm{R}$ & -.025 & .172 & 1 & & & & & & & \\
\hline & Sig. & .434 & .127 & & & & & & & & \\
\hline \multirow[t]{2}{*}{ Log(Ind_PE) } & $\mathrm{R}$ & -.103 & -.045 & $-.329 *$ & 1 & & & & & & \\
\hline & Sig. & .248 & .384 & .013 & & & & & & & \\
\hline \multirow[t]{2}{*}{$\log (\mathrm{RONW})$} & $\mathrm{R}$ & -.043 & .135 & -.019 & .137 & 1 & & & & & \\
\hline & Sig. & .388 & .186 & .451 & .182 & & & & & & \\
\hline \multirow[t]{2}{*}{ Log(NAVES) } & $\mathrm{R}$ & $.313^{*}$ & $.372^{*}$ & $.325^{*}$ & -.068 & -.016 & 1 & & & & \\
\hline & Sig. & .017 & .005 & .014 & .326 & .457 & & & & & \\
\hline
\end{tabular}


Pricing Determinants of selected Fixed Price IPOs issued in India

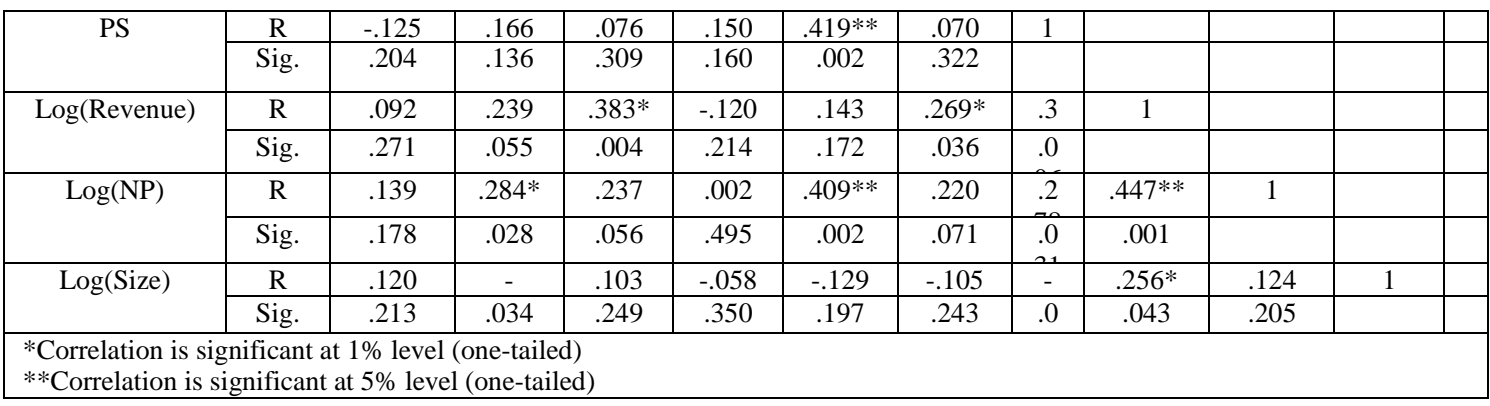

One way to find the dependence of offer price and listing price on selected variables is through the correlation among the variables. Various quantitative variables are taken in such a way as they represent two categories: firstly, the variables listed in the prospectus of the company and secondly those with a history in affecting the pricing of the IPOs. All the variables listed in the above table are: $\log (\mathrm{OP}), \log (\mathrm{LP}), \log (\mathrm{age})$, $\log (\mathrm{RONW}), \log$ (NAVES), PS, $\log ($ Revenue $), \log (\mathrm{NP}), \log ($ Size $), \log \left(\mathrm{Ind} \_\mathrm{PE}\right)$ and EPS.

Table 4- Correlation Coefficient List

\begin{tabular}{|l|l|}
\hline \multicolumn{2}{|c|}{ Offer Price } \\
\hline $\log ($ NAVES $)$ & $0.313^{*}$ \\
\hline $\log ($ NP) & 0.139 \\
\hline $\log ($ Size $)$ & 0.12 \\
\hline $\log ($ Revenue $)$ & 0.092 \\
\hline EPS & 0.0091 \\
\hline $\log ($ Age $)$ & -0.025 \\
\hline $\log ($ RONW) & -0.043 \\
\hline Log(Ind_PE) & -0.103 \\
\hline PS & -0.125 \\
\hline
\end{tabular}

\begin{tabular}{|l|l|}
\hline \multicolumn{2}{|c|}{ Listing Price } \\
\hline $\log ($ NAVES $)$ & $0.372^{* *}$ \\
\hline $\log ($ NP) & $0.284^{*}$ \\
\hline $\log ($ Revenue $)$ & 0.239 \\
\hline $\log ($ Age $)$ & 0.172 \\
\hline PS & 0.166 \\
\hline $\log ($ RONW $)$ & 0.135 \\
\hline EPS & 0.03 \\
\hline Log(Ind_PE $)$ & -0.045 \\
\hline Log(Size $)$ & $-0.271^{*}$ \\
\hline
\end{tabular}

TABLE 4 depicts insignificant correlation among the independent variables and the offer price except for $\log$ (NAVES) which reflects a significant correlation with the OP. While on the other hand, the LP is correlated significantly with three variables namely $\log (\mathrm{NAVES}), \log (\mathrm{Size})$ and $\log (\mathrm{NP})$. It is clear from the table that LP is positively related to NAVES and NP signifying that increase in the value of these variables leads to the increment in the LP as well, whereas Size is negatively correlated with the LP which implies that the issues with larger sizes have lower listing prices and vice versa. The table lists the variables according to their correlation coefficient with the dependent variables in the descending order of the coefficient values from the most positive to the most negative value. It is clear that for both the dependent variables NAVES turned out to be the most correlated variable in the study. And the next in turn, correlated variable is NP in both the cases however it is statistically significant only for the LP. Considering the negative coefficient, only size has got a significant correlation with the LP, while OP has no variable with significant negative correlation but the Ind_PE and PS has value of -0.103 and -0.125 respectively. Negative correlation with PS illustrates that as the promoter's retention in the shareholding decreases, the OP increases and vice versa.

\subsection{Emphirical Methodology}

Influenced by the earlier trend in literature we use the following econometric model:

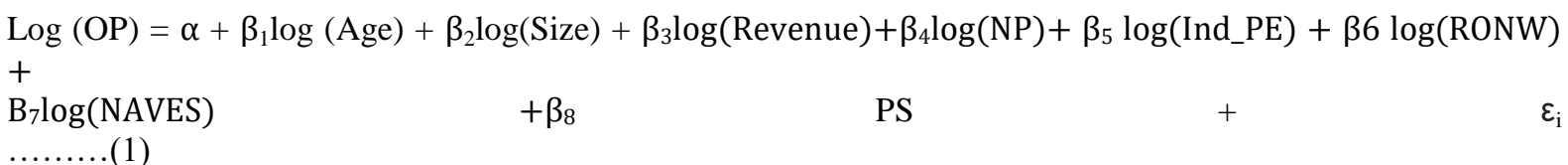

$\log (\mathrm{LP})=\alpha+\beta_{1} \log ($ Age $)+\beta_{2} \log ($ Size $)+\beta_{3} \log ($ Revenue $)+\beta_{4} \log (\mathrm{NP})+\beta_{5} \log ($ Ind_PE $)+\beta 6 \log (\mathrm{RONW})$ $+$

$\mathrm{B}_{7} \log (\mathrm{NAVES})$

$+\beta_{8} \quad$ PS

$\varepsilon_{\mathrm{i}}$

\subsection{Offer Price (OP) Model}

The result for multivariate regression for $\mathrm{OP}$ has been reported in the Table 5. The table represents the coefficients of independent variables as related to the dependent variable OP. It could be seen that NAVES, NP, Revenue and Size are positively related with the OP while Age, RONW, Ind_PE ratio and PS related to the OP. 
Table 5- Offer Price Regression Model

\begin{tabular}{|c|c|c|c|c|c|}
\hline \multirow[t]{2}{*}{ Model } & \multicolumn{2}{|c|}{ Unstandardized Coefficients } & $\begin{array}{l}\text { Standardized } \\
\text { Coefficients }\end{array}$ & \multirow[t]{2}{*}{$\mathrm{t}$} & \multirow[t]{2}{*}{ Sig. } \\
\hline & $\mathrm{B}$ & Std. Error & Beta & & \\
\hline \multirow{9}{*}{$\begin{array}{c}\text { (Constant) } \\
\log \text { Age } \\
\log \text { Ind_PE } \\
\text { log RONW } \\
\log \text { NAVES } \\
\text { PS } \\
\text { log Revenue } \\
\text { logNP } \\
\log \text { Size }\end{array}$} & .813 & .785 & & 1.036 & .307 \\
\hline & -.167 & .124 & -.246 & -1.350 & .185 \\
\hline & -.062 & .087 & -.119 & -.720 & .476 \\
\hline & -.006 & .054 & -.021 & -.115 & .909 \\
\hline & .159 & .075 & .360 & 2.135 & .040 \\
\hline & -.171 & .312 & -.120 & -.549 & .586 \\
\hline & .013 & .058 & .048 & .220 & .827 \\
\hline & .031 & .046 & .125 & .669 & .508 \\
\hline & .065 & .109 & .118 & .595 & .555 \\
\hline \multicolumn{6}{|c|}{$\begin{array}{l}\text { Summary: } \\
\mathrm{R}=.429 \\
\mathrm{R}^{2}=.184\end{array}$} \\
\hline \multicolumn{6}{|c|}{$\begin{array}{ll}\text { a. } & \text { Predictors: (Constant), } \log \text { Size, } \log \text { Ind_PE, } \log \text { NP, } \operatorname{logNAVES,~} \log \text { Revenue, log RONW, log Age, PS } \\
\text { b. } & \text { Dependent Variable: } \log \text { OP }\end{array}$} \\
\hline
\end{tabular}

The coefficient values represent that only NAVES is related to the OP at $5 \%$ significance level with the regression coefficient value of .159. This implies that other variables being constant, a unit change in the NAVES will lead to a change of .159 in the OP. It explains that the OP moves in the same direction as the change in NAVES.

Besides NAVES, Revenue and NP are also positively related with the OP, although the coefficient values are very small, .013 and .031 respectively. Increased Revenue and profits of a company signify the goodwill of the company and seems to attract more investors and stakeholders but their influence over the OP is not significant. Further, Size is also positively related to the OP with regression coefficient of 0.065 . The table further reveals that the coefficients of PS and Age of the company are -.167 and -.171 which implies their inverse relation with the offer price, although they are not statistical significant in this study. Earlier studies Suchard and Singh $(2007)^{[23]}$ have revealed that the older the firm the greater is the price OP but the present study has shown a contrasting result that matured firms have lower OP as compared to the newer firms. Also the greater the PS means lower OP for the IPO.

RONW and Ind_PE also appeared to be negatively related with the OP. However the results of the study in context to RONW and Ind_PE turned out contrasting as compared to the previous studies and researches. RONW implies the goodwill of the firm and thus the companies with higher RONW must be having higher prices however study revealed a negative relation. Also Ind_PE implies the industry is performing well and the IPO price must be higher but the study results are otherwise. Although the coefficients are small and they are not statistically significant either but they have shown a negative effect on IPO offer prices. The overall model did not turn out to be quite significant. The value of $R^{2}$ is 0.184 which implies that the selected variables only explains a small proportion of the offer price i.e. only $18.4 \%$ of the variability of the offer price of IPOs floated through fixed price mechanism in the time period of 2010-2016.

\subsection{Listing Price Model}

The multivariate regression for LP has been reported in the following table 6. The table represents the coefficients of independent variables as related to the dependent variable LP. It could be seen that Age, Ind_PE, RONW, NAVES, Revenue and NP are positively related with the listing price while Size and PS are inversely related to the listing price.

Table 6- Listing Price Regression Model

\begin{tabular}{|c|c|c|c|c|c|}
\hline \multirow{2}{*}{ Model } & \multicolumn{2}{|c|}{ Unstandardized Coefficients } & \multirow{2}{*}{$\frac{\text { Standardized Coefficients }}{\text { Beta }}$} & \multirow{2}{*}{$\mathrm{t}$} & \multirow{2}{*}{ Sig. } \\
\hline & $\mathrm{B}$ & Std. Error & & & \\
\hline \multirow{9}{*}{$\begin{array}{c}\text { (Constant) } \\
\text { logAge } \\
\log \text { Ind_PE } \\
\log \text { RONW } \\
\log \text { NAVES } \\
\text { PS } \\
\text { log Revenue } \\
\text { log NP } \\
\log \text { Size }\end{array}$} & 2.650 & .854 & & 3.103 & .004 \\
\hline & .007 & .135 & .009 & .053 & .958 \\
\hline & .001 & .094 & .002 & .012 & .991 \\
\hline & .015 & .059 & .044 & .261 & .796 \\
\hline & .118 & .081 & .229 & 1.449 & .156 \\
\hline & -.305 & .340 & -.183 & -.898 & .375 \\
\hline & .078 & .063 & .248 & 1.224 & .229 \\
\hline & .058 & .050 & .204 & 1.166 & .251 \\
\hline & -.257 & .118 & -.403 & -2.172 & .037 \\
\hline \multicolumn{6}{|l|}{$\begin{array}{l}\text { Summary: } \\
\mathrm{R}=0.537 \\
\mathrm{R}^{2}=0.289\end{array}$} \\
\hline
\end{tabular}


The Size is negatively related with the listing price with regression coefficient -0.257 at significance level of $5 \%$. Which implies that as the Size increases by one unit, LP decreases by -0.257 , other variables being constant. The two show an inverse relationship. Moreover, PS tend to have an inverse relationship as shown by the results. Though they might not be statistically significant but the value is -0.305 which is quite high to denote an influential variable. This implies that when more of the shares are retained by the promoters themselves then the LP tends to be lower.

The NAVES has a positive impact on the LP with the regression coefficient value .118. This entails that more the asset value, more is the LP. Further, Revenue and NP also has positive relation with the LP with values 0.078 and 0.058 , respectively, this could be devoted to the fact that increased revenue and net profit refers to the upward mobility of the company and hence the LP be likely to increase. Lastly, RONW, Ind_PE and Age have a positive relation but the coefficient value is so low that they don't seem to have practically impacted the LP of fixed price IPOs for the period of the study. The overall model can be explained with the help of $R^{2}$ which signifies the validity of the model. The selected variables do not explain much of the listing price of the fixed price IPO issued in 2010-2016 as $R^{2}$ value is only .289

i.e. only $28.9 \%$ of the variability of the LP is explained by the model.

\subsection{Findings}

\section{Findings And Conclusion}

Thus, it is found in the study that only NAVES turned out to be significantly correlated to the OP at $1 \%$ significance level. While in context to the LP, NP and Size turned out to be significantly correlated to it at $1 \%$ level with NP positively correlated while Size is correlated negatively. Further, NAVES is positively correlated to the LP at 5\% significance level. Apart from them NP and Size tend to be positively correlated with OP whereas Ind_PE and PS are negatively correlated to OP. However, Revenue, Age and RONW has shown a very low level of correlation. For LP, Revenue, Age, PS and RONW are positively correlated whereas Ind_PE has shown a very inferior correlation with the LP. The multivariate OLS regression model for the offer price and listing price explains only $18.4 \%$ and $28.9 \%$ of the dependent variables. Thus the selected variables do not explain much of the variability of these dependent variables.

\subsection{Conclusion}

In this project, various parameters are computed for their contribution in the variability of the IPOs issued through fixed price mechanism in the time period of 2010-2016. The variables included are checked for their merit in previous studies and research papers. The independent variables are listing price and offer price for the fixed price IPOs, while the independent variables list include age of the company, issue size, return on net worth, revenue, net profit, promoter's shareholdings, net asset value per share and industry composite price earning ratio. Earlier studies have shown these variables to be of significant impact on the pricing of the IPOs. However, the same does not hold true in the present study. As most of the variables have not shown any significant impact on the pricing points, neither was there a significant correlation among these dependent and independent variables except for a few.

In context to the correlation among the variables, the study evaluated that only Net asset value per share has got a significant correlation with the offer price, and Net asset value per share, issue size and net profit have got a significant correlation with the listing price. Further, the model is able to explain only a small portion of the variability of both the prices. As only Net asset value per share and issue size has shown a significant impact on the offer price and listing price, respectively.

Thus it can be concluded that, variability of IPO pricing depends a number of factors and the factors chosen might have shown a significant variability of the IPO pricing for previous studies but for the present study they are not efficient and many other factors could also be considered to compute the variability factors. Moreover, the macro environment could also be the reason for the IPO pricing factor's variability. Macro environment factors include the political and economic environment of the country which includes factors like interest rates, inflation rates, currency value, and financial stability and so on. Apart from them, there are many other factors which could affect the IPO pricing such as the subscription rate, percentage of shares made available to public, cash flows, sales, research and development. Other qualitative factors may also have impact on the IPO pricing. These factors may include, the company's management, operating history etc. Thus there is wider future scope for this study wherein more variables could be incorporated in the empirical model on the basis of logical reasoning past literature so aas to build a more efficient model for price valuation of an IPO. 


\section{References}

[1] Bhattacharya, S., Imperfect Information, Dividend Policy, and the Bird in the Hand Fallacy, The Bell Journal of Economics, 10(1).1979,259-270.

[2] Ross, S.A., The Determination of Financial Structure: The Incentive-Signaling Approach, The Bell Journal of Economics, 8(1) , 1977, 23-40.

[3] Hughes, Patricia J., Signaling by Direct Disclosure under asymmetric information,. Journal of Accounting and Economics, 8(2), 1986, 119-142.

[4] Cassia E. A., IPO Underpricing in Italy, Applied Financial Economics, 14(3), 2004, 179- 194

[5] Pastor \& Veronesi, Rational IPO Waves, The Journal of Finance, 60(4), 2005, 1713- 1757.

[6] Adams Michael, Thornton Barry and Hall George (2008), IPO pricing phenomena: Empirical evidence of behavioral biases,Journal of Business and Economics Research, 6(2), 2008, 67-74.

[7] Gupta Jyoti \& Samdani Taufique, Is Investor sentiment driven by IPO pricing mechanism?Evidence from India, Journal of Finance, Issue No. 5, 2010, 106- 112.

[8] Krinsky, I., \& Rotenberg, W. , The valuation of initial public offerings, Contemporary Accounting Research, 5(2), 1989,501-515.

[9] Benveniste, L. M., \& Busaba, W. Y. , Bookbuilding vs. Fixed Price: An Analysis of Competing Strategies for Marketing IPOs. Journal Of Financial \& Quantitative Analysis,32(4), 1997, 383-403.

[10] Barker, R. G., Survey and market-based evidence of industry-dependence inanalysts' preferences between the dividend yield and price-earnings ratio valuation models, Journal of Business Finance and Accounting 26(3-4), 1999 , 393-418

[11] Bradshaw, M. T. , The use of target prices to justify sell-side analysts' stock recommendations, Accounting Horizons 16(1), 2002, $27-41$

[12] Aggarwal, R., Allocation of initial public offerings and flipping activity, Journal of Financial Economics 68, 2003,111-135.

[13] Yin-Hua Yeh, Pei-Gi Shu and Re-Jin Guo, Ownership Structure and IPO Valuation--Evidence from Taiwan. Financial Management (Wiley-Blackwell), 37(1), 2008, 141-161.

[14] Pukthuanthong K. \& Varaiya N., IPO Pricing, Block Sales, and Long-Term Performance, The Financial Review ,42, 2007, 319348

[15] Lin, C. T. \& Hsu, S. M., Determinants of the initial IPO performance: evidence from Hong Kong and Taiwan, Applied Financial Economics 18(12) 2008, 955-963.

[16] Smart, S. B. \& Zutter, C. J. , Dual class IPOs are Underpriced less severely. The Financial Review 43, 2008, 85-106

[17] Aggarwal, R., Bhagat, S., \& Rangan, S., The Impact of Fundamentals on IPO Valuation. Financial Management (Wiley-Blackwell), 38(2), 2009, 253-284.

[18] Lowry Michelle, Office Micah S. and Schwert G. William, The variability of IPO initial returns, The Journal of Finance, 140(2), 2010,425-466

[19] Álvarez, S., Pricing IPOs: An Approach for Spanish Firms. Journal of Finance and Bank Management, 3(1), 2015, 60-76.

[20] Yong, O., Cheap IPO: Does it matter. The Journal Of Developing Areas. 50(5), 2016, 454- 460.

[21] Jindal, M. , Analysis of IPOs price performance. The Catalyst- Journal Of Management, 1(1), 2016, 2455-7927

[22] Ritter Jay R., The long run performance of initial public offerings, Journal of Finance ,46(1), 1991, 3-27

[23] Suchard J \& Singh J , Determinants of the Pricing of Privatization IPOs in the UK and Australia. International Journal of Business, 12( 3), 2007, 1083-4346.

[24] Cotter Julie, Michelle Goyen and Sherryl Hegarty, Offer pricing in Australian Industrial Public Offers, Accounting and Finance, 45(1), 2005, 95-125

[25] Ghicas Dimitros C, Iriotis Nikolaos, Papadaki Aphroditi and Walker Martin, Fundamental Analysis and Valuation of IPOs in the construction Industry, International Journal of Accounting, Vol. 35(2), 2000, 227-241.

[26] Klein, A. 1996. "Can Investors Use the Prospectus to Price Initial Public Offerings." The Journal of Financial Statement Analysis, 23-39.

IOSR Journal of Business and Management (IOSR-JBM) is UGC approved Journal with S1. No. 4481, Journal no. 46879.

Harmohan Singh Dhall. "Pricing Determinants of selected Fixed Price IPOs issued in India." IOSR Journal of Business and Management (IOSR-JBM) 19.7 (2017): 113-121. 